\title{
From manga to stage: An adaptation study of 2.5-D musical live spectacle naruto-akatsuki no shirabe-
}

\author{
I Putri ${ }^{1}$ and H Pratama ${ }^{2}$ \\ ${ }^{1}$ Japanese Studies Program, Faculty of Humanities, Universitas Indonesia \\ 1irayna.putri@ui.ac.id, himawan@ui.ac.id
}

\begin{abstract}
This study aims to describe the content presentation process of 2.5-D musicals (theatre performances from stories of popular Japanese culture such as anime, manga, and game) of NARUTO -Akatsuki no Shirabe- (hereafter referred to as $N A R U T O-A n S-$ ) from manga to on-stage performance and to understand the motivation behind its adaptation. This study is conducted through text analysis method in order to map the presentation difference from manga to on-stage theatre, and through literature study. From this study it is found that there are several adjustments in NARUTO-AnS- in order to fulfil requirements in its new medium, though in some areas still remain loyal to its adapted work. Its loyalty towards the adapted work is to fulfil requirements of the new medium; to meet its creative an economic motivations. This study reveals that in accordance to Balodis' theory, loyalty towards the adapted work is based on two motivations, creative and economical motivation.
\end{abstract}

Keywords: manga, musical, naruto

\section{INTRODUCTION}

Starting from the $2000 \mathrm{~s}$ a new form of performance art, namely $2.5-\mathrm{D}$ musical, attracts Japanese popular culture fans both inside and outside Japan. Simply put, 2.5-D musical is a theatre performance displaying adaptation stories from works from various forms of popular culture (j25musical.jp). According to [1], the term "2-5-D" emerged from Japanese popular culture fans, which see it as a form of art which enable them to see their 2-dimensional favourite popular culture in the form of "real life" theatre (3-dimension). The 2.5-D musical genre gained popularity in 2003 after the adaptation of the highly popular manga Prince of Tennis into a musical production, which was performed at the prestigious Tokyo Metropolitan Theater.

Similarly, the globally acclaimed manga series by Kishimoto Masashi, Naruto, was adapted into 2.5-D musicals. One of which is NARUTO-Akatsuki no Shirabe- (hereafter referred to as NARUTO - AnS-). The manga follows the story of Naruto, a young ninja who desires recognition from his friends and fellow villagers, and aspire to be a Hokage, the leader of his village. The story in NARUTO-AnS-depicts the pursuit of Sasuke (Naruto's school teammate). Naruto who just returned to his village after a two and half year of honing his skills, learns about Orochimaru while working on his missions. Naruto is determined to search for Orochimaru's location to bring Sasuke home. However, Naruto, whom inside his body lies the locked up Kyuubi (a nine tailed fox monster), is targeted by an organization named Akatsuki who seeks for power by using Kyuubi. NARUTO $-A n S$-, the third theatre adaptation for Naruto, depicts 
the story from the second part of the manga called Naruto: Shippuden, ranging from the manga's volume 27 through 44.

Ref [2] explains that adaptation works into theater performances can be seen as a transposition of a work, a creative and interpretative process including reinterpretation and recreation, along with intertextuality values through its adaptation work. Thus, by referring to this explanation, 2.5-D musicals, such as NARUTO $-A n S-$, are also a part of these adaption works and are placed equally with other adaptation works. However, considering that 2.5-D musical is a new genre of adaptation works, there is a need to understand the difference between 2.5-D musicals and other adaptation works.

As a new genre in the entertainment world, 2.5-D musicals attract fascination among researches including [3] who attempts to define 2.5-D musicals from a theatre point of view, though interestingly, also expresses pessimism towards the future of 2.5-D musicals. Another researcher is Masuyama who discusses the potentials of 2.5-D musicals to bring influence to the Japanese entertainment world [4], and also address the issue through a musical point of view [5]. Through both works, Masuyama highlights the potentials of 2.5-D musicals in adding diversity in the Japanese musical industry. Studies of adaptation work include the study by [6] on adaptations of novel into a television series. The study exhibits a set of framework for adaptation researches by including other aspects of the work, and not only focusing on the "loyalty" towards the original work. Cardwell states that excessive "loyalty" towards its original work can also indicate ignorance towards adaptation values. With reference to the framework by Cardwell stated above, [7] formed the theatre adaptation, replacing the adaptation of television series to theatre shows, into adaptation of novels to theatre shows. Balodis attempts to form a flexible analysis model of theatre adaptation to give space for adaptation works to stand as its own work and not just as a duplicate of the original work.

The explanation above shows the availability of researches on adaptation works, though none has raised the discussion on 2.5-D musicals as an adaptation work. Using Balodis' textual analysis framework on $N A R U T O-A n S$-, this study intends to explain the characteristics of 2.5$\mathrm{D}$ musicals as an adaptation work of Japanese popular culture such as anime, manga, and game. Furthermore, this study tries to analyze the objectives of adapting a work into a 2.5 -D musical format.

\section{ANALYSIS OF LIVE SPECTACLE NARUTO-AKATSUKI NO SHIRABE-}

\subsection{Comparative Analysis}

Generic, Authorial, and Theatrical Context. The first step of the research framework by Balodis is identifying the genre of the adaptation works (generic context). This step is done by analysing intertextual and extratextual elements. Intertextuality is links between a text and other text in various forms like reference, imitation, etc. While, extratextuality refers to elements outside the text. It could be the sender of the text or the audiences. Intertextual elements are shown by the story plot and the costumes of NARUTO - AnS - that is faithful to the ones shown in the manga as it is. In addition, there are also certain narrations reproduced into a song and become a characteristic of the musical production. There's also an alteration of how the narration is being delivered due to the nature of the new medium. Extratextuality elements include how the show is indeed promoted as an adaptation of the Naruto manga. This indicates that story plot and promotion wise, the NARUTO $-A n S$ - stays true to its original work.

Expectations from the audience towards the adaptation work can also be inflicted through authorial context, in this case, the scriptwriter or the director of the theatre version, moreover if 
the scriptwriter or the director has already gained positive reputations in producing a performance work. In $N A R U T O-A n S$-, the person in charge of scriptwriting and directing is Kodama Akiko. She is known as a director of Takarazuka theater productions, a theatre group famous for their women-only cast. After retiring from Takarazuka, Kodama becomes part of the Japan 2.5-Dimensional Musical Association. 2.5-D musical productions by Kodama include Kuroshitsuji-Tango of the Campania- and LIVE IMPACT Attack on Titan. These adaptations attempts to stay loyal to the original work by portraying scenes as if straight from the manga, supported by costumes in line with the character designs in the story, and stage properties and backdrops attempting to reconstruct the scenes as if portrayed in the manga. The role of Kodama Akiko as both scriptwriter and director of $N A R U T O-A n S$ - becomes a quality assurance for the fans of 2.5-D musical adaptation works.

Theatrical context discusses about the medium used in an adaptation work. Adjusting to its new medium in the form of theatre, the Naruto manga, originally a written text, is turned into a musical production. As a musical theatre, the musical elements become an important part. In a musical production, aside from dialogues, narrations are also conveyed through song lyrics.

The elements stated above causes the need for adjustments in the shift in medium; from manga to theatre. The story presented in NARUTO-AnS- (2017) is an adaptation of volume 28 to 44 of the manga. Due to the limitation of the duration of theatre performance, the whole story is compressed and only several scenes related to the main story line are chosen and presented. As a stage performance, visual elements such as background and stage effects become an important part to convey the story to its audience. In NARUTO -AnS-, many scenes utilize a multimedia projector, especially during combat scenes, to present effects similar to the ones portrayed in the manga. One example is when Naruto releases the Füton Rasenshuriken. The image of the scene from the manga is brought on stage through the use of an image projector. This is done to maintain the loyalty to its illustration in the manga.

\subsection{The Mechanics of Narrative}

\subsubsection{Order}

. Order can be defined as a sequence of event or plot. "Order" becomes an important element in considering the adaptation when a theatre adapter obtains permission to turn the adapted story into a fabula, which is a raw material that can be arranged according to the need and requirements of the new medium [7]. In other words, the adapter is able to arrange the story as needed, and is not fixated to the plot given by the adapted story. In the $N A R U T O-A n S$ - theater performance, the chronology of events is loyal to its manga plot, which uses the progressivereverse plot. The reverse plot is used during a flashback scene, for instance when Tobi (a member of Akatsuki) informs Sasuke about Itachi's motive of assassinating his own family. In the manga, the speech bubble in the scene does not have a sign of direction, indicating that the speaker is not in the same scene. While in theatre, the lighting technique is used to differ rooms, blue lights for the room of the character narrating the story, and orange to define the room portraying the past story. The use of this technique is to maintain the loyalty of the stage performance with its adapted manga plot.

\subsubsection{Duration}

Duration" is a complex relationship determining the timing of narration, between the time needed to read a novel or watch a movie, with how long the fictional scenes actually take place within the story. The story presented in NARUTO-AnS-includes the story plot from the Naruto 
manga volume 28 to 44 . One of the challenges of the adaptation is presenting a story of seventeen manga volumes into a two and a half hour theatre performance. The situation requires certain scenes be removed from the manga or transformed to fit the new duration and medium of theatre. For example, in the manga, the flashback scene is portrayed in nine detailed pages of illustration; of young Sasuke wanting to train with Itachi but is rejected, and of other characters such as their parents. However, this scene is only shown through projection for 10 seconds, without portrayals of their parents or other scenes of Sasuke and Itachi. The need for the adjustment is due to duration requirements, though the scenes maintain loyalty to the main story plot thus reducing the parts where it is seem less important.

\subsubsection{Frequency}

"Frequency" in this context is defined as the number of times a scene in the story happens compared to the number of times the scene is mentioned or revisited in the text. According to [7], this strategy in a musical production can be used through the repetition of the music pattern known as reprise. This strategy is being used in the NARUTO $-A n S-$. As a musical theatre performance, aside from using dialogues, narrations are often conveyed through song lyrics. There is a same song repeatedly used but the main content of the lyric remains the same.

For example, there's a song sang by Sasuke in the beginning of the performance and the end of the performance with similar lyrics. The song narrates Sasuke who intends to assassinate his older brother, Itachi. The lyric of the song explains that in order to fulfil his ambition to kill his brother, no matter how dark the path he faces, he will pass it for the sake of gaining the bigger power. If the part of the song is attributed to the context of "frequency", the scene portrayed here is of Sasuke stating that he is determined to fulfil his revenge towards his brother. The scene is mentioned again in the theatre performance in the form of reprise. The use of reprise is necessary to keep the loyalty towards the adapted work through the song lyric as the narration. It is also a crucial element in maintaining the loyalty to its musical genre; through the use of song to convey narration

\subsubsection{Adapting the Narrator}

Contrary to a novel, which nature of the narrator is third person omniscient narrator, the narration in a manga is built upon dialogues between the characters or through a monologue, and is rarely lead by a narrator. This leads to an easier adaptation to the theatre medium since stage performances tend to use dialogues to build narration. Dialogues in NARUTO-AnS-tend to stay true to its original work. Many dialogues are made the same with the manga with only minor changes.

For example, in the scene where Tsunade gives the mission to Naruto and his team. In the theatre adaptation, dialogues from the two pages of manga showing aforementioned scene follows the exact dialogues from the speech bubble in the manga with minor changes. The change is due to requirements of the different medium as a shift from manga to theatre. In the manga, there is a subordinate of Tsunade delivering the information received from Sunagakure village, while in the theatre version Tsunade's subordinate is absent. As a replacement, Tsunade herself delivers the message straight to Naruto and his team. In addition, in the theatre version, Tsunade's dialogue is altered to bridge the sequence of event. Therefore, the additional dialogue functions as a way to inform audience that Naruto has just came back from a mission.

\subsubsection{Point of View}


The term "point of view" is ambiguous as there are different elements contributing in a production including the writer, actor, and music composer, with every contributor creating their own narration point of view (Stam, in [7]). Therefore, the role of the director is to highlight which elements are needed to convey the story. To deal with it, Stam offers a solution by adapting the concept of "focalization" from Genette to differ each narrator and to recognize how big the narrator sees and understands the story.

Referring to the categorization, the point of view in NARUTO-AnS-is part of the variable internal focalization, which is when the knowledge of the narrator is on the same level as the character. In a performance, the narration of the story is built from the dialogues between characters and in this study includes song lyric since the performance is part of a musical theater, therefore there is no presence of a narrator who knows the story plot more than the characters.

\subsection{Musical as an Adaptation Work}

The analysis stated above illustrates how as a product of adaptation from manga to theatre, NARUTO

$-A n S$ - attempts to preserve the loyalty of its adapted work. The change of medium requires adjustment in genre, and even in the way the narration is delivered. Moreover, there is a need to compress the story from a seventeen volume manga into a theatre production with 2.5 hour duration.

"The appeal of adaptations for audiences lies in their mixture of repetition and difference, of familiarity and novelty" [2]. In NARUTO $-\mathrm{AnS}-$, repetition and familiarity is portrayed through costume and makeup of the actors resembling the characters in the original work, with dialogues referring to the real speech bubbles of the manga. Furthermore, there is a difference value of the characters and scenes that are not brought to the performance, and novelty in the songs performance that certainly is unavailable in the manga, as a way to deliver the narration.

As stated by [2], adaptation works can be seen as a transposition from a work, creative process, and interpretative involving reinterpretation and reproduction, and containing intertextual values from the adapted work. NARUTO - AnS- as a 2.5-D musical contains those values as an adaptation work.

\subsection{Motivation of Producing Adaptation Work}

2.5-D musicals as a work adapting Japanese manga, anime, and game into an art performance may raise questions: why is there a need to adapt a work that has already succeeded in the market? Wouldn't there be reactions from existing fans who compares it with the original work, or the on stage portrayal is not in accordance to the imagination of fans? There are several reasons why adaptation is done on a work ([2], [7]), though here I will only highlight two motivations in line with the production $2.5-\mathrm{D}$ musicals, which are creative and economic reasons.

\subsubsection{Creative Motivation}

Seeing from a creative and aesthetic point of view, 2.5-D musical allows an adjustment of medium (for instance from the Naruto manga to NARUTO-AnS-) with a variety of technique. The difference of medium from the original work to the adaptation work demands creativity from the adapter to adjust the displayed content. There is a freedom in presenting a story from manga to theatre, for instance in the use of stage technology, properties, and lighting technique. However, this freedom is still bound to the adapted work by being loyal to the elements of the 
adapted work. Adaptation works that are disloyal to their original works would not meet the expectations of the fans.

As an adaptation work, 2.5-D musicals demand their adapter to adjust the medium from the adapted work to the theater medium. In this shift of medium, there is a need for the capability and creativity of the screenwriter and director to bring the story to the stage. The shift in medium will naturally take into account the new medium, in this case theater, by not forgetting its loyalty to the adapted work (manga). How 2.5-D musical maintains its loyalty to the original works can be seen as a way to meet the expectation for the fans of the adapted work. This is an important factor to take into account, as it can be assumed that the consumers of adaptation work are directly related to the production income.

\subsubsection{Economic Motivation}

By adapting a well-known work with existing fans, it can be assumed that 2.5-D musicals have already obtained the market share of fans from the adapted work. Therefore, the trend to choose a work that has large market potentials to be adapted is also for economical purposes. The adaptation of the Naruto manga, which is a popular manga worldwide, also shows its economical purposes.

There is also the presence of Japan 2.5-Dimensional Musical Association as the implementers of this economical purpose. Japan 2.5-Dimensional Musical Association is an association formed in 2014 with the aims to promote and develop 2.5-D musical works. In addition to promoting 2.5-D musicals inside and outside Japan, this association also conduct surveys on the industry, organizing seminars and training for association members, and develop new content. This association also manages a theatre in Shibuya exclusively for 2.5-D musical performances, which is the AiiA 2.5 Tokyo Theater, since 2015. 2.5-D musicals are a work supported by the government of Japan through Cool Japan. Referring to the official website of the Prime Minister of Japan, Cool Japan is defined as: "Cool Japan' generically refers to Japanese products, contents, and cultures that non-Japanese people considered cool". This shows that in general, Cool Japan refers to Japanese products, with contents and cultures considered as "cool" by foreigners and spreading it as a way to deepen exchange. The Japanese government with aims to strengthen the country's economy constructs the Cool Japan Initiative. Japanese popular cultures promoted in the Cool Japan Initiative are contents (manga, music, video games, etc), fashion, culinary, toys, and tourism [8]. Through the adaptation of works from contents promoted by Cool Japan, it can be assumed that 2.5-D musicals utilizes the popularity of those contents, both inside and outside Japan to introduce Japanese content, which eventually leads to the national income. Hence in certain points, 2.5-D musical contains similar motivations with Cool Japan Initiative.

\section{CONCLUSION}

This paper has shown that, in its process of adapting from manga to musical, NARUTO $A n S$ - has undergone various adjustments. These adjustments are necessary mainly because of the difference between the two mediums in their nature in delivering the narrative. In the case of NARUTO $-A n S-$, adjustments include the reduction of the number of scenes and characters from the manga version due to the limitation of duration of the musical show. Another adjustment is the use of musical performances as one of the modes of narrative delivery, which does not exist in the medium of manga. Regardless of the differences between the two mediums, we have witnessed how $N A R U T O-A n S$ - makes every effort to maintain 'loyalty' to its original manga version. For example, the use of costumes and make-up of actors refers to the appearance 
of characters in their manga. The dialogues in 2.5-D musical version also, in most cases, reflect the same dialogues as in speech bubbles in the manga. NARUTO-AnS-also uses projection techniques to recreate the background settings and various effects as seen in the manga version. As Hutcheon (2006) puts it, the appeal of adaptation works lies in the mix of repetition and difference, as well as familiarity and novelty of the works.

Thus, it is fair to say that for the audiences the mix of similarities and differences with the original version is one of the attractions presented by NARUTO $-A n S$ -

Drawing on [2] and [7] views on the motivation of the creation of adaptation works, this study identifies that at least the motivation of the adaptation of manga to 2.5-D musical as in $N A R U T O-A n S$ - could be divided into two motivations, i.e., creative motivation and economic motivation. As described in the previous section, the presence of differences with their original works is a standard feature in many other examples of adaptation works. However, NARUTO

$-A n S$ - tends to be loyal to its original work. This study argues that this kind of "loyalty" is $N A R U T O-A n S-$ effort to meet the expectations of Naruto fans. The textual loyalty of NARUTO $-A n S$ - to its original manga version is an essential element in luring Naruto fans all over the world to pay attention to and to spend in 2.5-D musicals.

\section{REFERENCES}

[1] A. Sugawa, “2.5次元文化とは何か ?,” Seikyusha. [Online]. Available: https://yomimono.seikyusha.co.jp/jigenbukaron/jigenbunkaron01.html.

[2] L. Hutcheon, A Theory of Adaptation. New York: Routledge, 2006.

[3] Suzuki K, “2 - 5次元ミュージカル,” Kyoritsu J. arts Lett., vol. 63, pp. 1-11, 2017.

[4] K. Masuyama, “掲載誌 愛知県立芸術大学紀要,” Bull. Aichi Univ. Arts, vol. 44, pp. 127-138, 2014.

[5] K. Masuyama，“2.5 次元ミュージカル活性化の諸相： 演目と作曲家の 多元性に着眼して・増山 賢治. 愛知県立芸術大学紀要,”Bull. Aichi Univ. Arts, vol. 45, pp. 97-113, 2015.

[6] S. Cardwell, The Literature/Film Reader: Issues of Adaptation. UK: Scarecrow Press, 2007.

[7] J. Balodis, The Practice of Adaptation: Turning Fact and Fiction into Theatre. Australia: Queensland University of Technology, 2012.

[8] METI, “Creative Industries Policy," METI, 2012. [Online]. Available: http://www.meti.go.jp/english/policy/mono_info_service/creative_industries/creative industries.html. 